\title{
Novel hollow titanium dioxide nanospheres with antimicrobial activity against resistant bacteria
}

\author{
Carol López de Dicastillo ${ }^{* 1,2}$, Cristian Patiño ${ }^{1,2}$, María José Galotto ${ }^{1,2}$, \\ Yesseny Vásquez-Martínez ${ }^{3,4}$, Claudia Torrent ${ }^{4}$, Daniela Alburquenque ${ }^{5}$, \\ Alejandro Pereira ${ }^{2,6}$ and Juan Escrig ${ }^{2,5}$
}

\section{Full Research Paper}

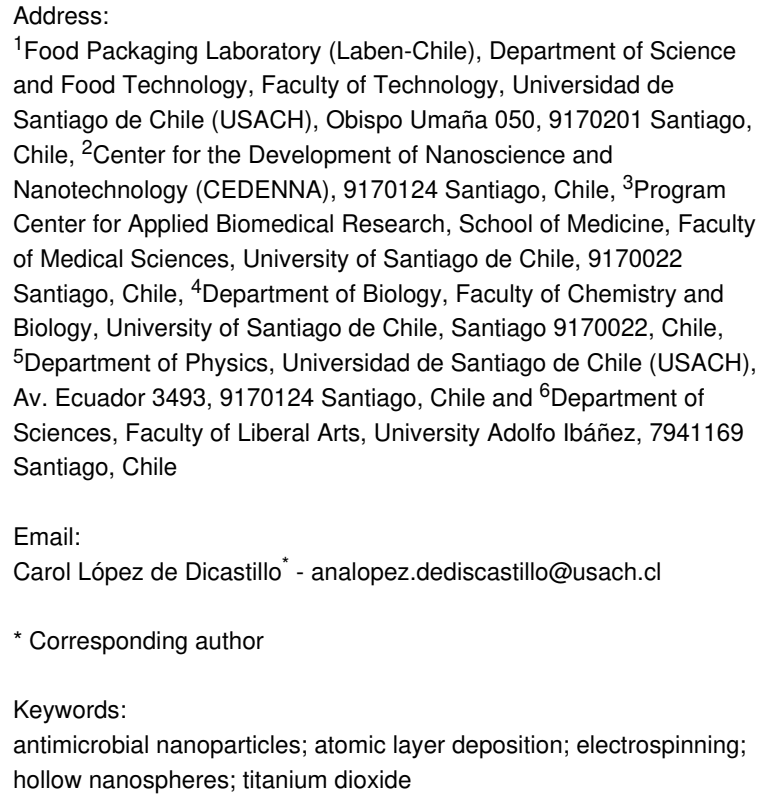

${ }^{1}$ Food Packaging Laboratory (Laben-Chile), Department of Science and Food Technology, Faculty of Technology, Universidad de Santiago de Chile (USACH), Obispo Umaña 050, 9170201 Santiago, Chile, ${ }^{2}$ Center for the Development of Nanoscience and Nanotechnology (CEDENNA), 9170124 Santiago, Chile, ${ }^{3}$ Program Center for Applied Biomedical Research, School of Medicine, Faculty of Medical Sciences, University of Santiago de Chile, 9170022 Santiago, Chile, ${ }^{4}$ Department of Biology, Faculty of Chemistry and Biology, University of Santiago de Chile, Santiago 9170022, Chile, ${ }^{5}$ Department of Physics, Universidad de Santiago de Chile (USACH), Av. Ecuador 3493, 9170124 Santiago, Chile and ${ }^{6}$ Department of Sciences, Faculty of Liberal Arts, University Adolfo Ibáñez, 7941169 Santiago, Chile

Email:

Carol López de Dicastillo* - analopez.dediscastillo@usach.cl

* Corresponding author

Keywords:

antimicrobial nanoparticles; atomic layer deposition; electrospinning; hollow nanospheres; titanium dioxide

Beilstein J. Nanotechnol. 2019, 10, 1716-1725. doi:10.3762/bjnano.10.167

Received: 21 March 2019

Accepted: 30 July 2019

Published: 19 August 2019

Associate Editor: J. J. Schneider

(C) 2019 de Dicastillo et al.; licensee Beilstein-Institut. License and terms: see end of document.

\begin{abstract}
The search for and synthesis of new antimicrobial nanostructures is important to reduce microbial incidence that induces infectious diseases and to aid in the antibiotic resistance crisis, which are two of the most pressing issues in global public health. In this work, novel, hollow, calcined titanium dioxide nanospheres $\left(\mathrm{CSTiO}_{2}\right)$ were successfully synthesized for the first time through the combination of electrospinning and atomic layer deposition techniques. Poly(vinylpyrrolidone) (PVP) electrosprayed spherical particles were double-coated with alumina and titanium dioxide, and after a calcination process, hollow nanospheres were obtained with a radius of approximately $345 \mathrm{~nm}$ and shell thickness of $17 \mathrm{~nm}$. The structural characterization was performed using electron microscopy, and X-ray diffraction and small-angle X-ray diffraction evidenced an anatase titanium dioxide crystalline structure. Thermogravimetric analysis and Fourier-transform infrared spectroscopy studies demonstrated the absence of polymer residue after the calcination process. The antimicrobial properties of the developed $\mathrm{CSTiO}_{2}$ hollow nanospheres were evaluated against different bacteria, including resistant $E$. coli and $S$. aureus strains, and when compared to commercial $\mathrm{TiO}_{2}$ nanoparticles, $\mathrm{CSTiO}_{2}$ nanospheres exhibited superior performance. In addition, the positive effect of UV irradiation on the antimicrobial activity was demonstrated.
\end{abstract}




\section{Introduction}

Microbial contamination and the increase of multidrug bacterial resistance have become two major current concerns for food safety and human health due to the number of food-borne diseases and nosocomial infections both in developed and developing countries worldwide [1]. Thus, the search for new alternatives against microbial incidence has become an important challenge. In this context, nanoparticles (NPs) have become of great interest to researchers because of their high reactivity against both Gram-positive and Gram-negative bacteria [2]. In recent years, metal and metal oxide NPs, such as silver, gold, titanium and zinc oxide NPs, have been extensively studied due to their interesting antimicrobial character [3-5]. Titanium dioxide $\left(\mathrm{TiO}_{2}\right)$ NPs have also attracted significant attention due to their high stability, low cost, reusability, and high photocatalytic activity [6-8]. These excellent properties have been applied in many products such as foods, catalyst support, air purification, water disinfection, antibacterial, cosmetics and solar cells $[9,10]$. Photocatalytic $\mathrm{TiO}_{2}$ favors the inactivation of microorganisms due to its strong oxidizing power by free radical generation, such as hydroxyl and superoxide anion radicals $[11,12]$.

Metal oxide NPs have been commonly synthesized by chemical and physical methods, which can produce a high size variability, defects and agglomeration and can reduce the effectiveness of their properties $[7,13,14]$. The use of chemical reducing agents causes the production of larger particles with extra energy consumption and commonly low stability. Thus, the use of controlled technologies to obtain NPs with improved properties has attracted great interest $[10,15]$. In this work, the combination of electrospinning and atomic layer deposition (ALD) technologies are presented as an innovative strategy to develop titanium dioxide hollow nanospheres with controlled and homogeneous dimensions. Electrospinning is a technique able to produce different nanostructures, such as fibers and spherical particles, through the application of a high voltage that breaks the surface tension of the droplet of a polymeric solution located at the tip of a needle $[16,17]$. The morphology of the result- ing nanostructures is influenced by the properties of the polymeric solution and the type of polymer. On the other hand, ALD is a novel metal oxide deposition process with excellent thickness control due to its low temperature processing and separated superficial reactions between precursor materials. Precursors are pulsed one by one over a substrate in the chamber and likewise purged to eliminate the unreacted substances and the by-product [18-20].

This is the first report on the development of metal oxide nanospheres synthesized using both electrospinning and ALD techniques. The resulting nanospheres were fully characterized by measuring the morphological, structural and thermal properties. In addition, the antimicrobial activity against common and multidrug-resistant bacteria were also studied. Crucial factors, such as the size, surface morphology and crystal structure of the NPs, were found to affect their antibacterial mechanism. Thus, the comparison of the antimicrobial activity of the developed hollow $\mathrm{TiO}_{2}$ nanospheres with commercial $\mathrm{TiO}_{2} \mathrm{NPs}$ was also performed.

\section{Results and Discussion Material characterization}

Titanium dioxide nanospheres were successfully obtained following the three-step procedure shown in Figure 1. First, electrosprayed spherical poly(vinylpyrrolidone) (SPVP) particles were obtained using a vertical electrospinning system. Subsequently, coated electrosprayed SPVP particles were obtained through the ALD process of $\mathrm{Al}_{2} \mathrm{O}_{3}\left(\mathrm{SPVP} \_\mathrm{Al}_{2} \mathrm{O}_{3}\right)$ and $\mathrm{TiO}_{2}$ (SPVP_Al $\mathrm{Sl}_{2} \mathrm{O}_{3} \mathrm{TiO}_{2}$ ) layers. Prior to the deposition of titanium dioxide, a very thin deposition of $\mathrm{Al}_{2} \mathrm{O}_{3}$ (alumina) was necessary with the role of fixing the SPVP particles to avoid their detachment during the $\mathrm{TiO}_{2}$ ALD step. Finally, the calcination process, carried out at $600{ }^{\circ} \mathrm{C}$ under an air atmosphere, was applied to remove the PVP polymer from the structures, resulting in hollow titanium dioxide nanospheres (calcined $\mathrm{TiO}_{2}$ spheres, $\mathrm{CSTiO}_{2}$ ).

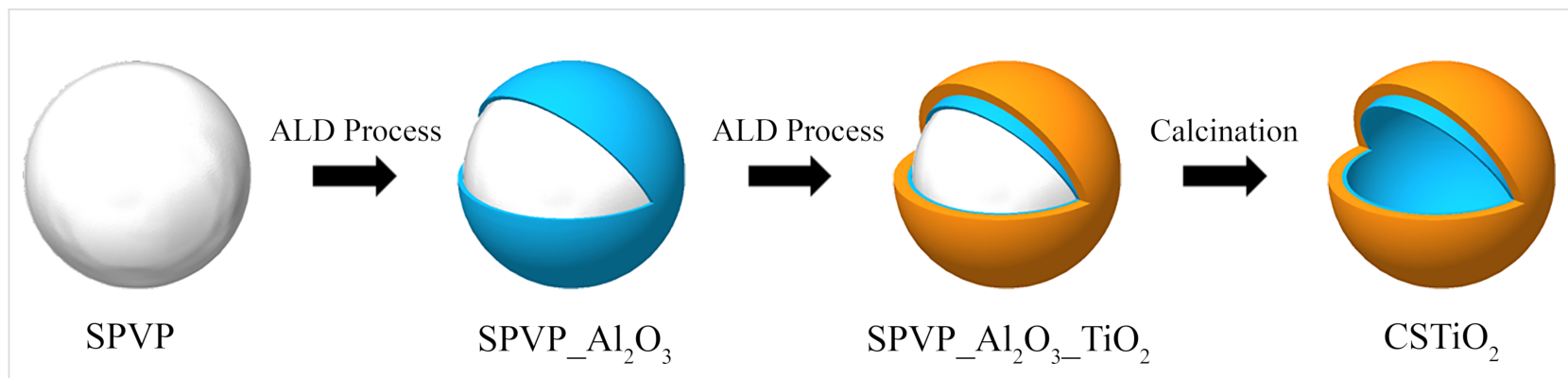

Figure 1: Three-step scheme to synthesize titanium dioxide nanospheres from electrosprayed SPVP spherical particles, resulting in hollow spheres after calcination, $\mathrm{CSTiO}_{2}$ 
Figure 2 shows photographs and scanning electronic microscopy (SEM) images of structures obtained through the three-step scheme displayed in Figure 1. As Figure 2e shows, SPVP particles were successfully obtained through a stable electrospraying process by using a $20 \%(\mathrm{w} / \mathrm{w})$ PVP polymeric solution. Unlike the common electrospinning process, which results in fibers by the continuous stretching of the Taylor cone through the application of a voltage to a polymeric solution with high viscosity, this case was considered an "electrospraying" process, which resulted in spherical particles due to the low-viscosity-based solution. In this process, the electric field generated monodisperse drops that contracted due to the fast evaporation of the solvent induced by Columbic explosion $[21,22]$.

Figure $2 \mathrm{a}-\mathrm{c}$ shows photographs of the three steps of the process: electrosprayed, alumina coated and alumina-titania double-coated particles. The alumina deposition maintained the initial white color of the collected electrosprayed spheres, while the $\mathrm{TiO}_{2}$ deposition acquired a dark bluish color. This change may be related to the number of deposition cycles that produced an optical interference due to the amount of deposited material $[18,23]$. SEM images presented in Figure 2e-g revealed that the morphology of the spheres was maintained after the depositions, ensuring uniformity and homogeneity.

Subsequently, $\mathrm{TiO}_{2}$-coated nanospheres underwent a calcination process at $600{ }^{\circ} \mathrm{C}$, resulting in the final, hollow nanostruc- tures. This thermal treatment produced a change of color to white (Figure 2d), which was associated with the change of the $\mathrm{TiO}_{2}$ crystalline structure. Furthermore, as Figure $2 \mathrm{~h}$ and Figure 3a-d show, SEM and transmission electronic microscopy (TEM) images confirmed that the spherical morphology was maintained after the calcination treatment.

Specifically, TEM images of $\mathrm{CSTiO}_{2}$ also evidenced the presence of holes in the walls of some nanostructures, which were likely produced due to the thermal degradation and release of the PVP polymeric backbone. In general, the thermal treatment at $600{ }^{\circ} \mathrm{C}$ did not generate enough pressure to break the nanosphere wall because of the double protection offered by the internal layer with $\mathrm{Al}_{2} \mathrm{O}_{3}$ and external layer with $\mathrm{TiO}_{2}$. TEM analysis also revealed that the total thickness obtained was approximately $16.8 \mathrm{~nm}$ after both ALD processes were performed (Figure 3c).

Energy dispersive X-ray (EDX) analysis was performed to determine the elemental composition of $\mathrm{CSTiO}_{2}$ and to confirm the presence of both $\mathrm{Al}_{2} \mathrm{O}_{3}$ and $\mathrm{TiO}_{2}$ layers. The EDX mapping results are shown in Figure 4a, where red, green and yellow colors correspond to oxygen, aluminum and titanium, respectively. The image did not present both layers separately, probably because the alumina layer was very thin and covered by the $\mathrm{TiO}_{2}$ layer. The peak corresponding to elemental titanium (Figure $4 \mathrm{~b}$ ) comprised the principal composition (38.8\%) of the sample. Additional analysis regarding the chemical composi-
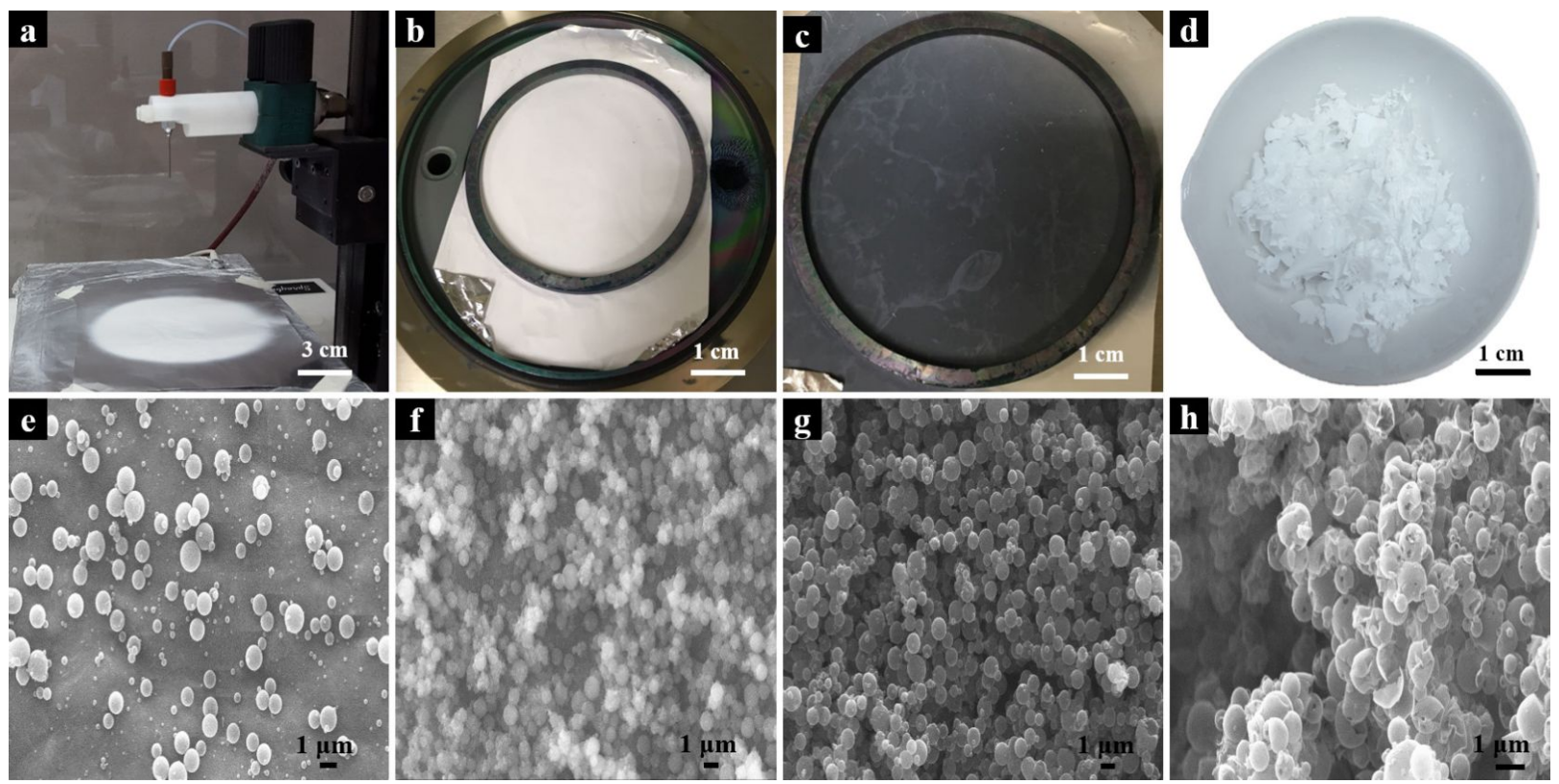

Figure 2: Photographs of: (a) electrosprayed spherical PVP particles (SPVP); (b) deposition of $\mathrm{Al}_{2} \mathrm{O}_{3}$ on SPVP by ALD (SPVP_Al $\mathrm{O}_{3}$ ); (c) deposition of $\mathrm{TiO}_{2}$ on the SPVP_ $\mathrm{Al}_{2} \mathrm{O}_{3}$ material by ALD (SPVP_ $\left.\mathrm{Al}_{2} \mathrm{O}_{3}-\mathrm{TiO}_{2}\right)$; (d) calcined samples $\left(\mathrm{CSTiO}_{2}\right)$; Scanning electronic microscopy (SEM) images of: (e) SPVP; (f) $\mathrm{SPVP}_{-} \mathrm{Al}_{2} \mathrm{O}_{3}$, (g) SPVP_Al $\mathrm{O}_{3} \mathrm{TiO}_{2}$; (h) $\mathrm{CSTiO}_{2}$. 


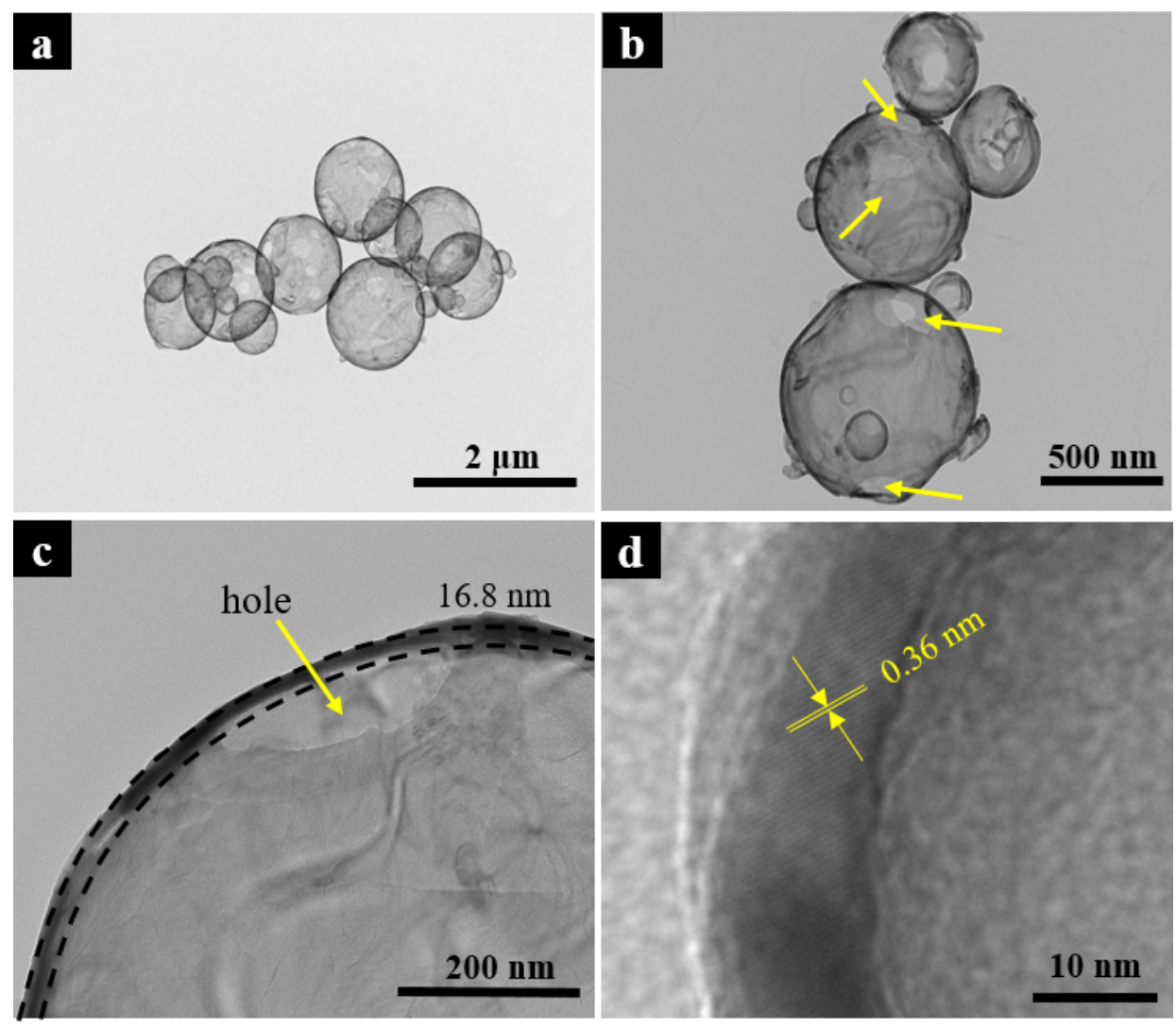

Figure 3: TEM images of calcined nanospheres, $\mathrm{CSTiO}_{2}$, at: (a) $2000 \times$; (b) $5000 \times$; (c) $10000 \times$ and (d) further details of the image in (c).

tion was also performed by Fourier-transform infrared spectroscopy (FTIR) in order to study the main functional groups of the sample (data found in Supporting Information File 1).

Thermogravimetric analysis (TGA) curves representing the mass loss with respect to temperature of SPVP, coated electrosprayed spheres (SPVP_Al $\mathrm{A}_{2} \mathrm{O}_{3}$ and SPVP_Al $\mathrm{Al}_{2} \mathrm{O}_{3} \mathrm{TiO}_{2}$ ), and $\mathrm{CSTiO}_{2}$ structures are shown in Figure 4c. Except for the $\mathrm{CSTiO}_{2}$ sample, the uncoated and coated samples presented mass loss between 5 to $10 \%$ below $100{ }^{\circ} \mathrm{C}$, corresponding to the dehydration process of the polymeric material in these structures. As expected, the TGA curves of structures containing PVP clearly evidenced both typical PVP degradation processes: i) the carbonic backbone decomposition around $200{ }^{\circ} \mathrm{C}$; and ii) pyrrolidone group decomposition between 350 and $470{ }^{\circ} \mathrm{C}$ [24-26]. TGA was used to verify two important facts: i) The calcination process effectively removed the PVP polymer, since $\mathrm{CSTiO}_{2}$ presented the same TGA curve as the commercial $\mathrm{TiO}_{2}$ NPs. TGA curves of $\mathrm{CSTiO}_{2}$ did not show any PVP degradation process thereby demonstrating that $\mathrm{CSTiO}_{2}$ was PVP-free. ii) The aluminum oxide and titanium dioxide deposited during the ALD processes were $(0.16 \pm 0.02) \%$ and $(23.41 \pm 0.47) \%$ with respect to the polymer weight, respectively. The deposi- tion of titania, when compared to our previous work, confirmed that the deposition onto the PVP polymer and polyvinyl alcohol presented a similar rate and it was mainly dependent on the number of cycles that determine the growth of thickness in the sample [18,27,28]. A small weigh loss of approximately $2 \%$ was found in $\mathrm{CSTiO}_{2}$, probably associated with the decomposition of hydroxyl groups on the titanium dioxide surface [29].

$\mathrm{X}$-ray power diffraction (XRD) analysis of the structures is shown in Figure 5. SPVP diffraction patterns showed a broad band with peak at $2 \theta$ equal to $20.3^{\circ}$ (solid line) corresponding to the amorphous nature of the PVP polymer [30-33]. Because they were independent of the samples, the peaks at approximately $11.2,30$ and $40^{\circ}$ corresponded to the noise baseline due to the nature of the samples. XRD diffractograms revealed that the calcination was an aggressive thermal treatment that resulted in an anatase $\mathrm{TiO}_{2}$ crystalline structure in the $\mathrm{CSTiO}_{2}$ sample [34-36]. Although previous works have mentioned that the anatase structure of $\mathrm{TiO}_{2}$ is a metastable structure, and can be irreversibly transformed into a stable rutile structure by heating, this process did not occur during calcination. The anatase-rutile transition occurs between 400 to $1000{ }^{\circ} \mathrm{C}$, and it is dependent on several parameters, such as the size of the nano- 

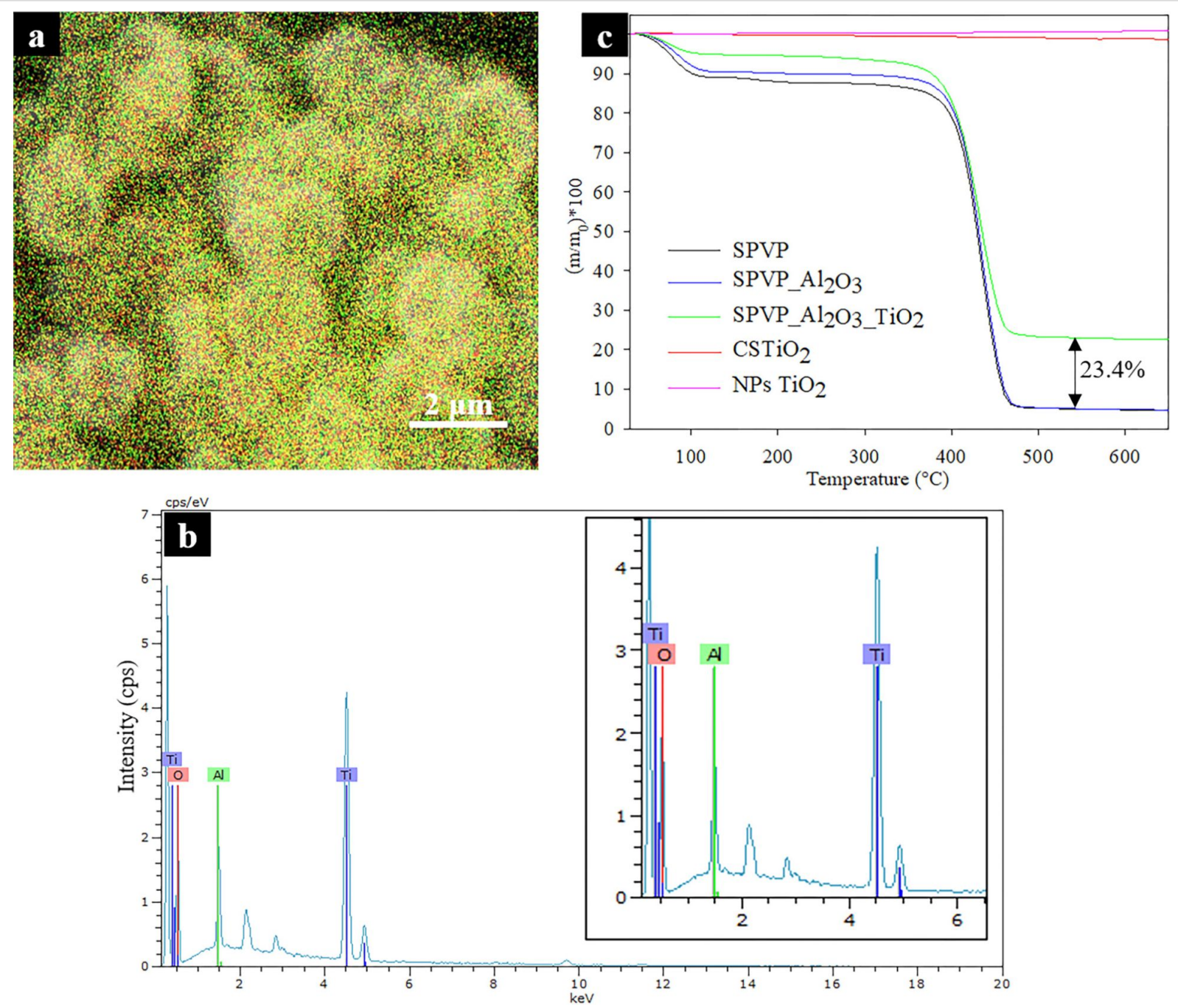

Figure 4: (a) EDX mapping marked with red (oxygen), green (aluminum) and yellow (titanium), (b) EDX spectrum of a CSTiO $\mathrm{SEM}$ image; and (c) TGA curves of the developed structures.

crystals, impurity content, microstructure and surface area. The necessary activation energy is high and the process is slow. In addition, some works have also confirmed that the anatase phase can be stable up to $600{ }^{\circ} \mathrm{C}$, and the rutile phase can be delayed to higher temperatures [36-38]. The anatase crystalline structure was confirmed by the presence of peaks at $25.28,37.8$, $48.05,53.89,55.06,62.69,68.76,70.31$ and $74.03^{\circ}$ (dashed lines). This crystalline structure can present promising antimicrobial activity due to the fact that several studies have declared that this structure presents the highest antimicrobial activity owing to its higher photocatalytic nature than rutile or brookite structures [39-41].

The small-angle X-ray scattering (SAXS) technique is a powerful technique that is based on the spatial fluctuations of the electronic density of the material that allows for the measurement of polymers, alloys, and amorphous materials, whose size varies between $1 \mathrm{~nm}$ and several hundreds of nanometers [42]. Figure 6 shows the $I(q)-q$ plot (SAXS curve) of the $\mathrm{CSTiO}_{2}$ structures. Additionally, the $q$ in the Figure 6 is the scattering vector and $I(q)$ is the intensity of scattering, respectively. The SAXS data were analyzed using the DIFFRAC.SAXS program that can fit and evaluate the size of the structures assuming different geometries. In this work, a core/shell particle was obtained with a particle radius of $345 \mathrm{~nm}$ and a shell thickness of approximately $17 \mathrm{~nm}$. These results revealed an excellent agreement with the data obtained from TEM images shown in Figure 3 .

\section{Antimicrobial activity}

The improved bioactivity of nanometer-sized $\mathrm{TiO}_{2}$ particles is due to the area of contact and/or volume that is increased by reducing the particle size, specifically in this case the thickness $(<100 \mathrm{~nm})$, which allows greater interaction with molecules and 


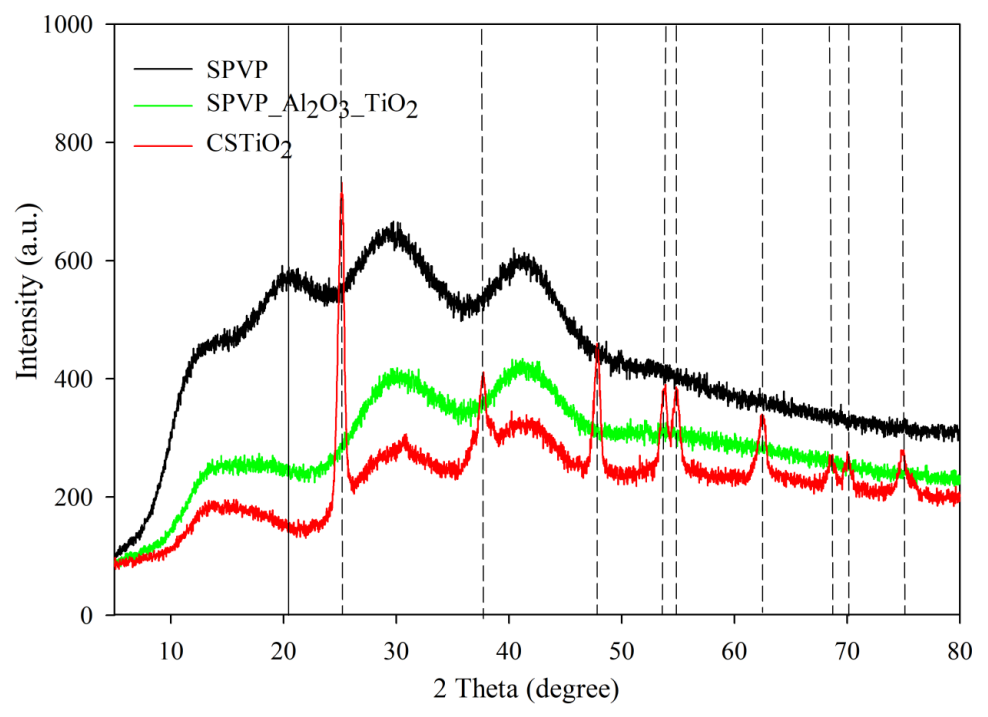

Figure 5: XRD diffraction patterns of: PVP electrosprayed spheres (SPVP), double coated spheres $\left(\mathrm{SPVP}_{-} \mathrm{Al}_{2} \mathrm{O}_{3} \_\mathrm{TiO}_{2}\right)$ and hollow TiO ${ }_{2}$ nanospheres $\left(\mathrm{CSTiO}_{2}\right)$.

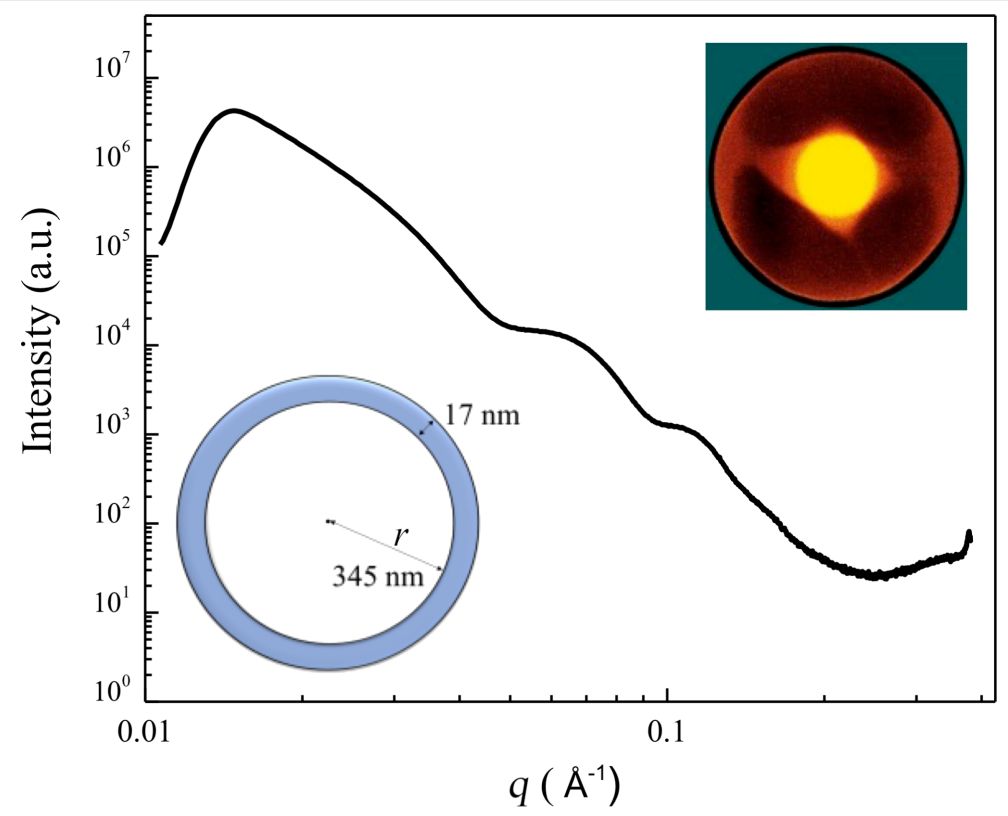

Figure 6: The $I(q)-q$ plot of $\mathrm{CSTiO}_{2}$ structures obtained by SAXS.

proteins of the cellular membrane and a lower amount of substance $[2,43,44]$. In this work, the evaluation of the antibacterial activity of $\mathrm{CSTiO}_{2}$ with a spherical morphology and nanoscale-thickness of approximately $17 \mathrm{~nm}$ was evaluated and compared with traditional $\mathrm{TiO}_{2}$ NPs. The reduction of thickness of these nanostructures was obtained by reducing the cycles of deposition during the ALD process $[18,45,46]$. The antibacterial activity of $\mathrm{CSTiO}_{2}$ and $\mathrm{TiO}_{2} \mathrm{NPs}$ was evaluated by the inhibition of growth of Staphylococcus aureus (control strain ATCC ${ }^{\circledR} 6538 \mathrm{TM}$ and resistant strain MRSA 97-7 and MRSA 622-4) and Escherichia coli (control strain ATCC ${ }^{\circledR} 25922 \mathrm{TM}$ and resistant strain E. coli 33.1 ). When the analysis was done using control strains, the results in Table 1 indicate that $\mathrm{CSTiO}_{2}$ presented an improved antibacterial activity against $\mathrm{S}$. aureus and a similar activity against $E$. coli in comparison with commercial $\mathrm{TiO}_{2}$ NPs. Nevertheless, when assays were carried out with resistant bacteria, only $\mathrm{CSTiO}_{2}$ presented promising antibacterial activity against $E$. coli MRSA 33.1. This low performance could be due to the increased multidrug resistance evidenced by some bacteria due to different mecha- 
Table 1: Percent inhibition of nanostructures against resistant and control bacterial strains.

\begin{tabular}{|c|c|c|c|c|c|}
\hline \multirow[t]{2}{*}{ Antimicrobial compound } & \multicolumn{5}{|c|}{ Percent inhibition of bacterial growth at $100 \mu \mathrm{g} \mathrm{mL}^{-1}$} \\
\hline & $\begin{array}{l}\text { S. aureus } \\
\text { ATCC6538 }\end{array}$ & $\begin{array}{l}\text { S. aureus } \\
\text { MRSA 97-7 }\end{array}$ & $\begin{array}{l}\text { S. aureus } \\
\text { MRSA 622-4 }\end{array}$ & E. coli ATCC25922 & E. coli MRSA 33.1 \\
\hline $\mathrm{CSTiO}_{2}$ & $20 \%$ & $0 \%$ & $0 \%$ & $40 \%$ & $7 \%$ \\
\hline $\mathrm{TiO}_{2} \mathrm{NPs}$ & $0 \%$ & $0 \%$ & $0 \%$ & $35 \%$ & $11 \%$ \\
\hline Vancomycin $\left(25 \mu \mathrm{g} \mathrm{mL}^{-1}\right)$ & $100 \%$ & $100 \%$ & $100 \%$ & - & - \\
\hline Ampicillin $\left(150 \mu \mathrm{g} \mathrm{mL}^{-1}\right)$ & - & - & - & $100 \%$ & $100 \%$ \\
\hline
\end{tabular}

nisms, such as reduced cell permeability, target overproduction and protection [47]. As Table 1 shows, the concentration of the strongest antibiotics commonly used against these bacteria were in the range of $25-150 \mu \mathrm{g} \mathrm{mL}^{-1}$.

In general, $\mathrm{CSTiO}_{2}$ exhibited higher antibacterial capacity against Gram-negative bacteria, such as control and resistant E. coli strains, than Gram-positive bacteria, such as $S$. aureus ATCC 6538, MRSA 97-7 and MRSA 622-4. Different mechanisms of antimicrobial activity can be exerted by NPs. Specifically, in the case of $\mathrm{TiO}_{2} \mathrm{NPs}$, previous works have declared bactericidal activity via reactive oxygen species (ROS) generation and disruption of bacteria cell walls in the case of $E$. coli, and release and reactions of ions with thiol groups belonging to proteins of the bacterial membrane of $S$. aureus $[48,49]$.

Probably, $\mathrm{CSTiO}_{2}$ presented better affinity and greater contact area with Gram-negative bacteria cells due to their cell wall structure, allowing a greater ROS formation. This tendency was already observed with $\mathrm{TiO}_{2}$ dioxide nanotubes developed in a previous work [18].

Due to the photocatalytic nature of titanium dioxide, different UV-A irradiation exposure times were studied in order to understand their effect on the antimicrobial activity of $\mathrm{TiO}_{2}$ nanostructures against $S$. aureus MRSA 97-7. The results shown in Table 2 validated that the antibacterial effect of $\mathrm{CSTiO}_{2}$ can be greatly increased due to the photocatalytic activity of these NPs in suspension. The antimicrobial performance of $\mathrm{CSTiO}_{2}$, induced by exposure to UV-A light $(<390 \mathrm{~nm})$, occurred generally through the generation of ROS and specifically from hydroxyl radicals $\left(\mathrm{OH}^{*}\right)$ (through electron abstraction from water) and superoxide anion radicals $\mathrm{O}_{2}{ }^{*}$ (generated by the reduction of $\mathrm{O}_{2}$ ). ROS incidence can attack microbial cells through various processes, such as lipid peroxidation of cell membrane, damaging DNA and/or amino acid- and proteinbased cell oxidation [50,51]. This analysis also evidenced that, although an important enhancement of $\mathrm{CSTiO}_{2}$ antimicrobial activity occurred within $60 \mathrm{~min}$ of UV irradiation, no further improvements in activity were observed with extended irradia-
Table 2: Effect of UV irradiation on the antimicrobial activity of nanoparticles at $100 \mu \mathrm{g} \mathrm{mL}^{-1}$. The percent inhibition of the $S$. aureus MRSA 97-7 strain against $100 \mu \mathrm{g} / \mathrm{mL}$ of $\mathrm{CSTiO}_{2}$ and $\mathrm{TiO}_{2} \mathrm{NPs}$ as a function of irradiation time is given.

\begin{tabular}{lllll} 
Nanoparticles & $\begin{array}{l}0 \text { min } \\
\text { irradiation }\end{array}$ & $\begin{array}{l}20 \text { min } \\
\text { irradiation }\end{array}$ & $\begin{array}{l}60 \text { min } \\
\text { irradiation }\end{array}$ & $\begin{array}{l}120 \text { min } \\
\text { irradiation }\end{array}$ \\
\hline $\mathrm{CSTiO}_{2}$ & $0 \%$ & $5 \%$ & $37 \%$ & $36 \%$ \\
$\mathrm{TiO}_{2} \mathrm{NPs}$ & $0 \%$ & $0 \%$ & $0 \%$ & $0 \%$
\end{tabular}

tion time. On the other hand, commercial $\mathrm{TiO}_{2}$ NPs did not present any antimicrobial activity against this resistant bacteria, even after a UV-irradiation time of $120 \mathrm{~min}$. This fact can be due to the high resistance of this microorganism to these antimicrobial NPs at this concentration. Thus, a series of $\mathrm{TiO}_{2} \mathrm{NPs}$ suspensions at increasing concentrations were examined over 60 min UV-irradiation. Assays revealed that commercial $\mathrm{TiO}_{2}$ NPs presented $28 \%$ reduction of $S$. aureus MRSA 97-7 strain at $300 \mu \mathrm{g} \mathrm{mL}^{-1}$.

\section{Conclusion}

This is the first report on the development of metal oxide nanospheres from the combination of electrospinning and atomic layer deposition processes. Although the purpose was the development of antimicrobial nanostructures based on titanium dioxide (due to its high photocatalytic nature), it was necessary to deposit a thin layer of alumina prior to the titania deposition to physically stabilize these low weight particles. Although previous works have demonstrated the successful deposition of metal oxides on nanofibers, the morphological change to spherical particles entailed a more difficult deposition process that was nevertheless successfully employed. Thus, hollow, spherical, antimicrobial nanostructures with a shell of $17 \mathrm{~nm}$ thickness were successfully obtained and antimicrobial results evidenced better performance than commercial $\mathrm{TiO}_{2}$ nanoparticles, principally against multidrug resistant bacteria such as the S. aureus strain. Antimicrobial tests also revealed that hollow $\mathrm{TiO}_{2}$ nanospheres present promising activity when irradiated with UV light. In addition to the antibacterial properties, these hollow nanospheres could be used for photocatalytic purposes. 
This represents a first work that opens up possibilities for the development of further nanostructures with different morphologies based on different metal oxides.

\section{Experimental}

\section{Chemicals and microorganisms}

Poly(vinylpyrrolidone) (PVP) (molecular weight 40.000), trimethylaluminium (TMA), tetrakis(dimethylamide)titanium (TDMAT) (99.99\% trace metals basis) and ethanol were obtained from Sigma Aldrich (Santiago, Chile). Texas Industrial Solutions Advanced (Santiago, Chile) supplied commercial titanium dioxide nanoparticles commonly used in industrial applications, named $\mathrm{TiO}_{2}$ NPs.

Two clinical isolates of methicillin resistant Staphylococcus aureus 622-4 and 97-7, and one clinical isolate of Escherichia coli 33.1 were kindly donated by Dr. Marcela Wilkens from Universidad de Santiago de Chile (Chile). Control strains, S. aureus ATCC6538 and E. coli ATCC25922, were also used and provided from the same source.

A UV-A lamp bulb with $15 \mathrm{~W}$ from Philips (model Actinic BL TL TL-D 15W/10 1SL/25) was used.

\section{Development of hollow $\mathrm{TiO}_{2}$ nanospheres}

Electrosprayed SPVP materials were obtained using a vertical electrospinning system (Spraybase ${ }^{\circledR}$ power supply unit, Ireland). A $20 \%$ (w/v) PVP solution was prepared in 50\% ethanol solution and stirred at room temperature until the polymer was completely dissolved. The solution was transferred to $5 \mathrm{~mL}$ plastic syringes and connected through a PTFE tube to a 20 -gauge blunt $(0.9 \mathrm{~mm}$ diameter) stainless steel needle charged by a high voltage power supply in the range of $0-20 \mathrm{kV}$. The parameters were previously optimized in order to obtain homogeneous spherical particles and the following values were used: flow rate $0.5 \mathrm{~mL} \mathrm{~h}^{-1}$, distance $12 \mathrm{~cm}$ and voltage $12.9 \mathrm{kV}$.

Coated electrosprayed SPVP particles were obtained through the deposition of $\mathrm{Al}_{2} \mathrm{O}_{3}$ and $\mathrm{TiO}_{2}$ layers using a Savannah $\mathrm{S} 100$ ALD device from Ultratech (San Jose, CA, USA) following the provider's recipes from Cambridge NanoTech. 50 cycles of $\mathrm{Al}_{2} \mathrm{O}_{3}$ deposition was carried out at $80{ }^{\circ} \mathrm{C}$ using TMA and ultrapure water as precursors. Both TMA and $\mathrm{H}_{2} \mathrm{O}$ were unheated. The pulse times of TMA and water in the TMA/water cycle were kept at $0.015 \mathrm{~s}$, while the exposure times in each half-cycle were $30 \mathrm{~s}$ and $60 \mathrm{~s}$, respectively. Subsequently, the $\mathrm{TiO}_{2}$ deposition process was performed using the combination of the TDMAT precursor agent and ultrapure water for 300 cycles. These precursors were alternatively introduced into the ALD chamber at $200{ }^{\circ} \mathrm{C}$ with a pulse time of 0.1 and
$0.015 \mathrm{~s}$, respectively, while the exposure times were $10 \mathrm{~s}$ in both cases. The temperature of the TDMAT and $\mathrm{H}_{2} \mathrm{O}$ solutions were set at $75^{\circ} \mathrm{C}$ and room temperature, respectively.

The calcination process was carried out at $600{ }^{\circ} \mathrm{C}$ for $1 \mathrm{~h}$ under air atmosphere.

\section{Characterization of structures: from SPVP to $\mathrm{CSTiO}_{2}$}

The morphology of each structure obtained through the entire process for the development of $\mathrm{CSTiO}_{2}$ was observed using SEM (Zeiss EVO MA10 SEM) at $20 \mathrm{kV}$. Electrosprayed SPVP particles, before and after the ALD processes, and hollow $\mathrm{CSTiO}_{2}$, obtained after the polymer template removal, were studied. $\mathrm{CSTiO}_{2}$ particles were also observed through TEM (Hitachi HT7700 high resolution TEM) at $100 \mathrm{kV}$. Additionally, the elemental composition of $\mathrm{CSTiO}_{2}$ was analyzed by SEM (Vega3 Tescan SEM) with an in-column EDX detector at $15 \mathrm{kV}$.

TGA was carried out using a Mettler Toledo Gas Controller GC20 Stare System TGA/DCS. The samples $(\approx 6 \mathrm{mg})$ were heated from 25 to $800{ }^{\circ} \mathrm{C}$ at $10^{\circ} \mathrm{C} \mathrm{min}^{-1}$ under nitrogen atmosphere (flow rate $50 \mathrm{~mL} \mathrm{~min}^{-1}$ ).

XRD patterns were measured using a Siemens diffractometer D5000 (30 mA and $40 \mathrm{kV})$ using $\mathrm{Cu} \mathrm{Ka}(\lambda=1.54 \AA)$ radiation at room temperature. All scans were performed in a $2 \theta$ range of $2-80^{\circ}$ at $0.02^{\circ} \mathrm{s}^{-1}$.

SAXS measurements were performed using a Bruker N8 Horizon SAXS system equipped with a $\mathrm{Cu} \mathrm{K} \alpha$ radiation $(\lambda=1.54 \AA)$ source and 2D VÅNTEC-500 and MONTEL optics. The data were acquired in the q-range from $0.012-0.37 \AA^{-1}$ with a measurement time of $14.400 \mathrm{~s}$ in vacuum ( 2 mbar) at room temperature. The generator was operated at a power of $1 \mathrm{~kW}$. The data processing and analysis were performed using a Bruker DIFFRAC.SAXS program.

\section{In vitro antibacterial activity assays using human pathogens}

The antimicrobial activity of $\mathrm{CSTiO}_{2}$ against $E$. coli ATCC®25922TM, E. coli multiresistant 33.1, S. aureus ATCC®6538TM and methicillin-resistant $S$. aureus 97-7 and 622-4 were determined using the microdilution method established by Clinical and Laboratory Standards Institute with some modifications [52]. Briefly, stock solutions $\left(5 \mathrm{mg} \mathrm{mL}^{-1}\right)$ of nanoparticles in water were sonicated for $3 \mathrm{~min}$ and diluted in Mueller-Hinton broth (MHB) to the different two-fold assay concentrations. The obtained solution was then added to the MHB and serially two-fold diluted (in a 96-well microplate). 
$15 \mu \mathrm{L}$ of inoculum at $5 \times 10^{6}$ colony-forming units (CFUs) per $\mathrm{mL}$, prepared in MHB, was then added in a final volume of $150 \mu \mathrm{L}$.

The effect of UV irradiation on the antimicrobial activity was investigated by irradiating the 96-well microplate with a UV-A lamp located $25 \mathrm{~cm}$ above the samples for $0,20,60$, and $120 \mathrm{~min}$ with $150 \mathrm{rpm}$ stirring at room temperature. The plates were sealed with a tight-fitting plastic cover and incubated at $37^{\circ} \mathrm{C}$ for $18 \mathrm{~h}$. The assays were performed in triplicate. In wells containing MHB, $15 \mu \mathrm{L}$ of inoculum served as a negative control. The antimicrobial activity of commercial $\mathrm{TiO}_{2} \mathrm{NPs}_{\text {was }}$ also evaluated in order to compare the effectiveness of both nanostructures.

\section{Supporting Information}

\section{Supporting Information File 1}

The study of structures through Fourier-transform infrared spectroscopy is described.

[https://www.beilstein-journals.org/bjnano/content/ supplementary/2190-4286-10-167-S1.pdf]

\section{Acknowledgements}

The authors acknowledge the financial support of CONICYT through the Project Fondecyt Regular 1170624, "Programa de Financiamiento Basal para Centros Científicos y Tecnológicos de Excelencia" (Project FB0807) and DICYT-USACH (grant No. 021601VM) and the Project Fondecyt 11171045.

\section{ORCID ${ }^{\circledR}$ iDs}

Carol López de Dicastillo - https://orcid.org/0000-0003-0067-9765 Juan Escrig - https://orcid.org/0000-0002-3958-8185

\section{References}

1. Dakal, T. C.; Kumar, A.; Majumdar, R. S.; Yadav, V. Front. Microbiol. 2016, 7, 1831. doi:10.3389/fmicb.2016.01831

2. Wang, L.; Hu, C.; Shao, L. Int. J. Nanomed. 2017, 12, 1227-1249. doi:10.2147/ijn.s121956

3. Rai, M. K.; Deshmukh, S. D.; Ingle, A. P.; Gade, A. K. J. Appl. Microbiol. 2012, 112, 841-852. doi:10.1111/j.1365-2672.2012.05253.x

4. Kadiyala, U.; Turali-Emre, E. S.; Bahng, J. H.; Kotov, N. A.; VanEpps, J. S. Nanoscale 2018, 10, 4927-4939. doi:10.1039/c7nr08499d

5. Siddiqi, K. S.; ur Rahman, A.; Tajuddin; Husen, A. Nanoscale Res. Lett. 2018, 13, 141. doi:10.1186/s11671-018-2532-3

6. Xu, Z.; Zhuang, C.; Zou, Z.; Wang, J.; Xu, X.; Peng, T. Nano Res. 2017, 10, 2193-2209. doi:10.1007/s12274-017-1453-2

7. Zhao, Z.; Zhang, X.; Zhang, G.; Liu, Z.; Qu, D.; Miao, X.; Feng, P.; Sun, Z. Nano Res. 2015, 8, 4061-4071. doi:10.1007/s12274-015-0917-5
8. Feng, X.; Pan, F.; Zhao, H.; Deng, W.; Zhang, P.; Zhou, H.-C.; Li, Y. Appl. Catal., B 2018, 238, 274-283. doi:10.1016/j.apcatb.2018.07.027

9. Qiu, K.; Durham, P. G.; Anselmo, A. C. Nano Res. 2018, 11 , 4936-4954. doi:10.1007/s12274-018-2137-2

10. Li, H.; Zhou, Q.; Gao, Y.; Gui, X.; Yang, L.; Du, M.; Shi, E.; Shi, J.; Cao, A.; Fang, Y. Nano Res. 2015, 8, 900-906. doi:10.1007/s12274-014-0571-3

11. Dhanasekar, M.; Jenefer, V.; Nambiar, R. B.; Babu, S. G.; Selvam, S. P.; Neppolian, B.; Bhat, S. V. Mater. Res. Bull. 2018, 97 , 238-243. doi:10.1016/j.materresbull.2017.08.056

12. De Falco, G.; Porta, A.; Del Gaudio, P.; Commodo, M.; Minutolo, P.; D’Anna, A. MRS Adv. 2017, 2, 1493-1498. doi:10.1557/adv.2016.665

13. Aytekin Aydın, M. T.; Hoşgün, H. L.; Dede, A.; Güven, K. Spectrochim. Acta, Part A 2018, 205, 503-507. doi:10.1016/j.saa.2018.07.063

14. Xu, Z.; Kan, Y.; Liu, C. Mater. Res. Bull. 2018, 107, 80-86. doi:10.1016/j.materresbull.2018.07.012

15. Pat-Espadas, A. M.; Cervantes, F. J. J. Chem. Technol. Biotechnol. 2018, 93, 3091-3112. doi:10.1002/jctb.5681

16. Liu, D.; Zhang, C.; Dong, G.; Xu, C.; Liu, D.; Lv, Y.; Zhong, B.; Wang, B. Mater. Res. Express 2018, 6, 015007. doi:10.1088/2053-1591/aae467

17. Liu, X.; Yang, Y.; Yu, D.-G.; Zhu, M.-J.; Zhao, M.; Williams, G. R. Chem. Eng. J. 2019, 356, 886-894. doi:10.1016/j.cej.2018.09.096

18. López de Dicastillo, C.; Patiño, C.; Galotto, M.; Palma, J.; Alburquenque, D.; Escrig, J. Nanomaterials 2018, 8, 128. doi:10.3390/nano8020128

19. Porro, S.; Bejtka, K.; Jasmin, A.; Fontana, M.; Milano, G.; Chiolerio, A.; Pirri, C. F.; Ricciardi, C. Nanotechnology 2018, 29, 495201. doi:10.1088/1361-6528/aae2ff

20. Ricci, P. C.; Laidani, N.; Chiriu, D.; Salis, M.; Carbonaro, C. M.; Corpino, R. Appl. Surf. Sci. 2018, 456, 83-94. doi:10.1016/j.apsusc.2018.06.021

21. Cui, L.; Liu, Z.-P.; Yu, D.-G.; Zhang, S.-P.; Bligh, S. W. A.; Zhao, N. Colloid Polym. Sci. 2014, 292, 2089-2096. doi:10.1007/s00396-014-3226-8

22. Munir, M. M.; Suryamas, A. B.; Iskandar, F.; Okuyama, K. Polymer 2009, 50, 4935-4943. doi:10.1016/j.polymer.2009.08.011

23. Edy, R.; Zhao, Y.; Huang, G. S.; Shi, J. J.; Zhang, J.; Solovev, A. A.; Mei, Y. Prog. Nat. Sci.: Mater. Int. 2016, 26, 493-497. doi:10.1016/j.pnsc.2016.08.010

24. Mallakpour, S.; Behranvand, V. Prog. Org. Coat. 2015, 86, 18-24. doi:10.1016/j.porgcoat.2015.03.004

25. Mallakpour, S.; Jarang, N. Polym. Bull. 2018, 75, 1441-1456. doi:10.1007/s00289-017-2100-5

26. Hulsey, S.; Absar, S.; Sultana, Q. N.; Sabet, S. M.; Mahfuz, H.; Khan, M. Polym. Compos. 2018, 39 (Suppl. 2), E1025-E1033. doi:10.1002/pc.24444

27. Kavre Piltaver, I.; Peter, R.; Šarić, I.; Salamon, K.; Jelovica Badovinac, I.; Koshmak, K.; Nannarone, S.; Delač Marion, I.; Petravić, M. Appl. Surf. Sci. 2017, 419, 564-572. doi:10.1016/j.apsusc.2017.04.146

28. Bishal, A. K.; Sukotjo, C.; Takoudis, C. G. J. Vac. Sci. Technol., A 2017, 35, 01B134. doi:10.1116/1.4972245

29. Xiao, Z.; Guo, P.; Sun, N. J. Appl. Polym. Sci. 2017, 134, 44377. doi:10.1002/app.44377

30. Mangalam, R.; Thamilselvan, M.; Selvasekarapandian, S.; Jayakumar, S.; Manjuladevi, R. Ionics 2017, 23, 2837-2843. doi:10.1007/s11581-016-1931-7 
31. Saroj, A. L.; Singh, R. K.; Chandra, S. Mater. Sci. Eng., B 2013, 178, 231-238. doi:10.1016/j.mseb.2012.11.007

32. Hong, H.-K.; Park, C.-K.; Gong, M.-S. Bull. Korean Chem. Soc. 2010, 31, 1252-1256. doi:10.5012/bkcs.2010.31.5.1252

33. Bai, J.; Li, Y.; Sun, L.; Zhang, C.; Yang, Q. Bull. Mater. Sci. 2009, 32, 161-164. doi:10.1007/s12034-009-0024-x

34. López de Dicastillo, C.; Roa, K.; Garrido, L.; Pereira, A.; Galotto, M. Polymers (Basel, Switz.) 2017, 9, 117. doi:10.3390/polym9040117

35. Kuchi, C.; Harish, G. S.; Reddy, P. S. Ceram. Int. 2018, 44, 5266-5272. doi:10.1016/j.ceramint.2017.12.138

36. Subhapriya, S.; Gomathipriya, P. Microb. Pathog. 2018, 116, 215-220. doi:10.1016/j.micpath.2018.01.027

37. Wang, Z.; Saxena, S. K.; Pischedda, V.; Liermann, H. P.; Zha, C. S. J. Phys.: Condens. Matter 2001, 13, 8317-8323. doi:10.1088/0953-8984/13/36/307

38. Mendoza-Anaya, D.; Salas, P.; Angeles-Chávez, C.; Pérez-Hernández, R.; Castaño, V. M. Rev. Mex. Fis. 2004, 50 (Suppl. 1), 12-16.

39. Yoganarasimhan, S. R.; Rao, C. N. R. Trans. Faraday Soc. 1962, 58, 1579-1589. doi:10.1039/tf9625801579

40. Nagalakshmi, M.; Karthikeyan, C.; Anusuya, N.; Brundha, C.; Basu, M. J.; Karuppuchamy, S. J. Mater. Sci.: Mater. Electron. 2017, 28, 15915-15920. doi:10.1007/s10854-017-7487-0

41. Purbia, R.; Borah, R.; Paria, S. Inorg. Chem. 2017, 56, 10107-10116. doi:10.1021/acs.inorgchem.7b01864

42. Shi, W. M.; Dai, X. J.; Yang, G. C.; Xu, Y.; Liu, Y. Mater. Sci. Forum 2013, 743-744, 831-836. doi:10.4028/www.scientific.net/msf.743-744.831

43. Esfandiari, N.; Simchi, A.; Bagheri, R. J. Biomed. Mater. Res., Part A 2014, 102, 2625-2635. doi:10.1002/jbm.a.34934

44. Cushing, B. L.; Kolesnichenko, V. L.; O'Connor, C. J. Chem. Rev. 2004, 104, 3893-3946. doi:10.1021/cr030027b

45. Pessoa, R. S.; dos Santos, V. P.; Cardoso, S. B.; Doria, A. C. O. C.; Figueira, F. R.; Rodrigues, B. V. M.; Testoni, G. E.; Fraga, M. A.; Marciano, F. R.; Lobo, A. O.; Maciel, H. S. Appl. Surf. Sci. 2017, 422, 73-84. doi:10.1016/j.apsusc.2017.05.254

46. Park, J. Y.; Choi, S.-W.; Kim, S. S. Nanotechnology 2010, 21, 475601. doi:10.1088/0957-4484/21/47/475601

47. Baptista, P. V.; McCusker, M. P.; Carvalho, A.; Ferreira, D. A.; Mohan, N. M.; Martins, M.; Fernandes, A. R. Front. Microbiol. 2018, 9 , 1441. doi:10.3389/fmicb.2018.01441

48. Li, Y.; Zhang, W.; Niu, J.; Chen, Y. ACS Nano 2012, 6, 5164-5173. doi:10.1021/nn300934k

49. Roy, A. S.; Parveen, A.; Koppalkar, A. R.; Ambika Prasad, M. V. N. J. Biomater. Nanobiotechnol. 2010, 1, 37-41. doi:10.4236/jbnb.2010.11005

50. Brunet, L.; Lyon, D. Y.; Hotze, E. M.; Alvarez, P. J. J.; Wiesner, M. R. Environ. Sci. Technol. 2009, 43, 4355-4360. doi:10.1021/es803093t

51. Fu, G.; Vary, P. S.; Lin, C.-T. J. Phys. Chem. B 2005, 109, 8889-8898. doi:10.1021/jp0502196

52. Barry, A. L.; Craig, W. A.; Nadler, H.; Barth Reller, L.; Sanders, C. C.; Swenson, J. M. Methods for Determining Bactericidal Activity of Antimicrobial Agents; 1999; Vol. 19.

\section{License and Terms}

This is an Open Access article under the terms of the Creative Commons Attribution License (http://creativecommons.org/licenses/by/4.0). Please note that the reuse, redistribution and reproduction in particular requires that the authors and source are credited.

The license is subject to the Beilstein Journal of Nanotechnology terms and conditions:

(https://www.beilstein-journals.org/bjnano)

The definitive version of this article is the electronic one which can be found at:

doi:10.3762/bjnano.10.167 